\title{
Por uma Geografia dos Outsiders: interpretação e aplicação da Lei 10.639 na rede municipal de Armação dos Búzios em sua relação com a Comunidade Remanescente do Quilombo da Rasa.
}

\author{
Autor: Thyago Faria de Araújo \\ Licenciado em Geografia pela FFP/ UERJ \\ E-mail: tfaffp@hotmail.com.
}

\section{Resumo}

Pretende-se neste trabalho analisar a experiência de aplicação da Lei Federal 10.639/03 nas escolas municipais que atendem as crianças e jovens da comunidade remanescente do quilombo da Rasa, no município de Armação dos Búzios, cuja rede é a única no Estado do Rio de Janeiro a criar uma disciplina, intitulada "Estudos Afro", para aplicar a referida Lei. Para isso analisei duas escolas situadas no bairro da Rasa, área periférica, com população predominantemente negra e onde está presente a comunidade remanescente de quilombo. Portanto o interesse é analisar qual o rebatimento desta experiência nos múltiplos atores inseridos nesse processo: Secretaria de Educação, equipe pedagógica das escolas, professores, alunos e a comunidade quilombola. A metodologia se desdobra em três dimensões apontadas por André (1995) sobre a complexidade do cotidiano da escola: i) a institucional ou organizacional, verificando as formas de organização do trabalho pedagógico; ii) a instrucional ou pedagógica, através da comparação da matriz curricular e do currículo praticado da disciplina criada e da análise do posicionamento dos professores de Geografia diante deste processo; iii) a sociopolítica/cultural, apontando a configuração sócio-espacial em que as escolas estão inseridas. No entanto se faz necessário para isto uma discussão sobre a realidade sócio-espacial e a história local do bairro, para entender como processos pretéritos contribuíram para uma série de transformações no lócus, configurando embates em torno do território, os quais constituem e são constituídos pelo espaço escolar. O final da minha pesquisa coincidiu com a extinção da disciplina no município, devido a não aceitação dela por parte da comunidade escolar (alunos, professores, dirigentes e pais), sendo considerada a religião protestante - professada pela maior parte da população 
do bairro - a maior resistência a aplicação da Lei, além de se comportar como uma prática de branqueamento do território, ou seja, das práticas culturais ligadas às matrizes africanas.

Palavras-chave: Lei 10.639 - Currículo - Ensino de Geografia - História Local

\section{Abstract}

It is intended this work to analyze the Federal law enforcement experience $10,639 / 03$ in municipal schools that serve children and youngsters of the community remaining quilombo of Rasa, in the town of Armação dos Búzios, 72 whose network is the only in the State of Rio de Janeiro to create a discipline, entitled "African Studies", to apply that law. For this I have looked at two schools located in the neighborhood of Rasa, peripheral area, with predominantly black population and where it is present the remaining community of quilombo. So the interest is to analyze which the batting this experience in multiple actors inserted in this process: Secretary of education, pedagogical staff of schools, teachers, students and the quilombola community. The methodology unfolds in three dimensions identified by André (1995) about the complexity of everyday life of the school: i) the institutional or organizational, verifying the pedagogical forms of work organisation; ii) pedagogical, instructional or through comparison of curriculum and syllabus practiced discipline created and analysis of the placement of teachers of Geography on this process; iii) the socio-political/cultural, socio-spatial configuration pointing in which schools are inserted. However it is necessary for this a discussion about the socio-spatial and local history of the neighborhood, to understand how previous processes have contributed to a series of transformations in locus, configuring shocks around the territory, which constitute and are constituted by the educational space. The end of my research coincided with the extinction of the discipline in the city, due to non-acceptance of it by part of the school community (students, teachers, principals and parents), being considered the protestant religion - professed by most of the population of the neighborhood the greater resistance to law enforcement, in addition to behave as a practice of laundering the territory, and the cultural practices linked to african arrays.

Key Words: Law 10,639 - Curriculum - Teaching Geography - Local History

\section{Introdução}

Diversos autores do pós-colonialismo vêm, nas ultimas décadas, ganhando espaço dentro do campo científico com uma crítica ao capitalismo que reconhece diversas possibilidades de relações de domínio-subjulgação. 


\section{REVISTA TAMOIOS}

Em outras palavras, trata-se de uma crítica não eurocêntrica ao eurocentrismo como uma resposta aos que vêem no marxismo a única forma de contestação e de saída das situações de exploração engendradas pelo capital. Essa crítica tem como objeto de análise as várias estratégias da modernidade para assegurar a existência do seu avesso: a colonialidade. Dentre as variadas estratégias de dominação/exploração/hierarquização uma é ressaltada por este trabalho, a racial. A raça é um fator crucial para a constituição do capitalismo a partir da inferiorização de povos não brancos, através da produção de estigmas e estereótipos de sociedades e espaços.

Toda essa discussão é trazida, num movimento ainda em construção, para a esfera do currículo, resignificando as suas teorizações.

Alguns teóricos do currículo apontam a necessidade de considerá-lo a partir de algumas dimensões que o compõem. Verifica-se uma disjunção entre intenção e realidade, onde há um distanciamento do currículo praticado para o oficial, o que é fruto de diversas implicações, como o tempo de aula e as disputas entre os diferentes atores pedagógicos, havendo todo um tensionamento de forças que faz com que nem sempre o que é planejado seja trabalhado.

Esses jogos de poder fazem da educação um cenário de constante disputa, no qual interferem múltiplas variáveis. A esse respeito Lopes (2006) nos diz que há um discurso hegemônico que cria instrumentos de homogeneização nas políticas de currículo, através do: i) discurso da cultura comum; ii) discurso da performatividade. O primeiro coloca a necessidade da seleção dos saberes mais legítimos e socialmente mais valorizados, enquanto que o segundo se instaura como uma forma de regulação dos sujeitos, ao apregoar o julgamento, a comparação, a competição e a responsabilização. Desse jeito os indivíduos são vistos a partir da sua performance, e criados para ver o conhecimento segundo o seu valor de troca (vantagens, um bom emprego, carro, casa, etc.) e não pelo seu valor de uso (para resignificar-se enquanto sujeito), passando este a ser algo passível de mensuração e todo conhecimento não adequado a ser apurado tem menor importância. Há então a defesa de um currículo comum, o que requer instrumentos de homogeneização como as práticas de avaliação centradas no resultado (nos mais diversos níveis 


\section{REVISTA TAMOIOS}

da educação, como a Prova Brasil, ENEM, ENAD, etc.) e os livros didáticos como guias da prática docente.

Portanto, verifica-se uma série de problemáticas que se colocam como entraves para o trabalho docente, onde qualquer prática educacional que se choque com as místicas da prescrição ii irá encontrar resistências de múltiplos atores e do próprio sistema educacional. Este fato tem contribuído para que o currículo escolar - e as disciplinas que o compõem - opere com uma matriz eurocentrada, ressaltando geografias, histórias, matemáticas, literaturas, etc. que refletem o ponto de vista da modernidade européia e sufocando outras.

No entanto, no ano de 2003 cria-se um aparato legal que abre a possibilidade de uma revisão desta matriz eurocentrada do currículo escolar com a aprovação da Lei Federal 10.639/03 $3^{\mathrm{iii}}$. Porém, como salienta Pereira (2008), há toda uma acomodação do sistema educacional que faz com que a Lei 10.639 entre no grupo das "leis que não pegaram!".

Diante desses fatos temos que nos indagar sobre: qual a pertinência da Lei 10.639? Que rumos tomaram a Lei dentro das escolas? Como vem sendo ou não - aplicada a Lei? E, por fim, como a Geografia pode e deve contribuir para atender seus apontamentos?

Foi esta a preocupação que incentivou esta pesquisa, que se traduz num conjunto de questões: Diante de uma interpretação da Lei tida, a priori, como "conservadora" - houve a criação de uma Disciplina para atender a Lei Federal 10.639/03 na Rede Municipal de Armação dos Búzios - como se portaram os professores de Geografia no que concerne a implementação da Lei dentro do referencial teórico-metodológico da sua Disciplina? E que discussões realizava esta nova Disciplina? Como se deu esta experiência única no Estado do Rio de Janeiro de criação de uma Disciplina específica para trabalhar os conteúdos colocados pela Lei? Qual a importância desse trabalho para a cidade, visto que num de seus bairros - Rasa - está situada uma Comunidade Remanescente de Quilombo? Qual a atuação dessa Comunidade Quilombola nesse processo de implementação da Lei? 


\section{REVISTA TAMOIOS}

\section{Apresentando a pesquisa}

Esta pesquisa é um estudo de caso de uma tentativa de implementação da Lei 10.639 a partir da criação de uma disciplina - Estudos Afro - na rede municipal de Armação dos Búzios. No entanto teve como recorte analítico o bairro da Rasa, por nele estar situada uma Comunidade Remanescente de Quilombo. A metodologia foi desdobrada em um processo de análise que passou por três dimensões: i) analisar a disciplina Estudos Afro, suas matrizes curriculares (currículo oficial), através da problematização da ementa oficial da disciplina e do "confronto" desta com o currículo praticado pelos professores através de entrevistas com docentes e com alunos e análise de materiais verificando o que tem de Geografia no escopo da disciplina; ii) analisar a disciplina de Geografia, verificando como se dá a relação com a disciplina Estudos Afro, ou seja, se com a criação de uma nova disciplina o ensino de Geografia nas escolas foi negligente em seu papel na aplicação da Lei, isto é, revendo a matriz eurocentrada que orienta as suas prescrições curriculares; o que foi feito através de entrevistas e questionários; iii) analisar como esses alunos - em sua maioria negros e descendentes direto de quilombolas - se enxergam a partir das duas disciplinas, através de entrevistas com alunos assim como análises de seus materiais e trabalhos -, gestores, professores, coordenadores e membros da comunidade remanescente do quilombo da rasa. Rasa. iv

Este "enxergar" por parte dos alunos se refere a em que medida 0 processo de ensino-aprendizagem a que eles estavam sendo submetidos contribuía para a construção e/ou resignificação de um projeto identitário de ser "quilombola". Por isso, entende-se aqui que mais do que atentar para os pontos de conteúdo colocados pela a Lei 10.639, temos que atentar também para a História Local. Nesta perspectiva Goodson (2007), Lopes (2006) e Macedo (2006) nos apontam algumas saídas. O primeiro nos fala de privilegiar o capital narrativo em detrimento do capital simbólico, de modo que a aprendizagem serviria para conhecer mais de si e para a configuração de um projeto identitário. Lopes nos coloca a necessidade de se hibridizar o global e o local, conformando um padrão "glocal”. Da mesma forma, para Macedo o currículo 


\section{REVISTA TAMOIOS}

deve ser visto enquanto um espaço-tempo de fronteira, onde culturas globais e locais negociam a sua existência.

Nesse sentido, será discutida a seguir, de forma breve, a atual realidade sócio-espacial do bairro da Rasa e como esta é reflexo de alguns processos históricos de sua ocupação. Todos os relatos que virão provém da análise de trabalhos de pesquisa realizados por ex-professores da rede municipal de Armação dos Búzios com a comunidade quilombola da Rasa e de relatos colhidos nesta pesquisa.

\section{Apresentação da realidade local}

O bairro da Rasa, local onde a pesquisa foi realizada, tem uma realidade sócio-espacial marcada pelo descaso e por uma menor importância dada pela administração municipal. Há claramente um corte racial que faz da Rasa a periferia do Município. A população do bairro - que é predominantemente negra e descendente de escravos - recebe um tratamento diferenciado por parte dos governantes locais como, por exemplo, com os não raros desvios de abastecimento de água e luz do bairro para atender às áreas mais valorizadas do município. Tal situação periférica foi e é sustentada, segundo um discurso hegemônico, pelo mito do isolamento das comunidades quilombolas. Esta concepção fica clara no relato de um padre local ao falar que na Rasa "devido ao isolamento não houve miscigenação, daí os negros da Rasa apresentarem, ainda hoje, a estatura acima da média e a pele bem escura. Tal concepção se instaura como um senso comum dentro do município de ver a situação periférica do bairro da Rasa como uma auto-segregação da comunidade quilombola.

O início das transformações socioeconômicas no bairro coincide com a decadência da agricultura e a crescente especulação imobiliária, quando as grandes fazendas foram vendidas para novos proprietários que passaram a empregar grandes extensões de pastos. A mão-de-obra dos negros passou a não ser mais absorvida e estes foram gradativamente expulsos das terras por eles arrendadas após a abolição da escravatura, através do trabalho nas terras de antigos fazendeiros (NORBERTO, 1854) fato que aparece nos relatos de um dos entrevistados: "trabalhavam três dias por semana nas terras dos 


\section{REVISTA TAMOIOS}

patrões." As principais atividades eram o café, a banana e a extração de madeiras nobres.

Fica instaurando então um processo de desterritorialização, marcando uma característica peculiar do quilombo da Rasa - e que persiste hoje na atual comunidade quilombola - que é a não concentração no chamado bairro da Rasa. Ou seja, há a dispersão dessas comunidades, como nos apontam os próprios informantes, por diversas localidades como Maria Joaquina, Botafogo e Vila Verde. A Rasa seria, para os entrevistados, um referencial territorial que marca a origem do quilombo, nas imediações da Praia Gorda ou Praia dos Negros.

Em diversos momentos ficam marcadas nos relatos dos entrevistados situações concretas de racismo vivenciadas pelos sujeitos da Rasa. Dentro do próprio campo religioso, a situação conflituosa está instaurada. Há, segundo os informantes, uma separação entre a "igreja do branco" (Igreja Católica) e a "igreja do negro" (Assembléia de Deus). As igrejas ficam uma em frente à outra. Segundo o Sr. Luís: "o padre vem de Búzios fazer culto aqui.

A questão religiosa, aliás, é uma das causas do abandono de práticas seculares dos negros da Rasa. O Jongo, a capoeira, a Folia de Reis cederam de vez lugar aos cultos das igrejas, sobretudo as protestantes. Um dos marcos desse processo é contado pelo Sr. Luís que, diga-se de passagem, é pastor da Igreja Assembléia de Deus. Segundo ele "tenho lembrança forte da primeira igrejinha, que era na casa da minha avó Donária, eu estava com 8 ou 10 anos... certamente era onde tinha o jongo, era a família que cantava o jongo, que tocava o jongo, que o povo dançava... No momento que essa família se tornou evangélica acabou o jongo, nunca mais dançaram o jongo. Logo que a família tornou-se crente o jongo terminou."

É por isso que venho vendo a influência da fé protestante no bairro da Rasa a partir da óptica do branqueamentov, nesse sentido mais do território que da população, uma vez que as práticas religiosas e manifestações culturais de matrizes afro-descendentes foram substituídas por práticas de matrizes euro-descendentes.

Toda essa transformação vivida hoje pelo bairro da Rasa, e isso é unânime entre os entrevistados, remontam a cerca de menos de 30 anos. 


\section{REVISTA TAMOIOS}

Como fatores principais dessas transformações, podemos apontar a construção de estradas que deram início ao tráfego de linhas de ônibus regulares, ligando a Rasa à Cabo Frio e à Búzios; o incremento do turismo e a projeção de Búzios nacional e internacionalmente, modificando o ritmo e as formas de vida dessas pessoas e a intensificação da especulação imobiliária.

Há cerca de três décadas a população do bairro tinha na agricultura e na pesca artesanal a sua principal fonte de vida. Atualmente com a forte especulação imobiliária, o solo agricultável começa a se tornar escasso, tendo assumido grande parte dos moradores do bairro a ocupação de trabalhos temporários, sujeitos a sazonalidade do turismo, e de baixa remuneração. Tal situação já traz reflexos ao bairro e à cidade como aumento da violência e problemas decorrentes de uma má alimentação, visto que a agricultura de subsistência, muito praticada pelos antigos moradores, hoje é inviável por conta do tamanho dos lotes.

A comunidade remanescente do quilombo da Rasa foi reconhecida pelo Governo Federal, mas as terras não foram ainda distribuídas e tituladas houve apenas a demarcação territorial. As áreas demarcadas são: cruzeiro, Alta da Rasa e parte da Marina (topo de morro). Ocorre que a especulação imobiliária não espera, e essas áreas vão sendo progressivamente ocupadas, em alguns pontos até por condomínios de classe média.

\section{Disciplina "Estudos Afro": Confrontando o currículo oficial e o currículo praticado!?}

No meio de toda esta complexidade de transformações sócio-espaciais (e, de avanço de um projeto local voltado para o turismo de alta renda, projeto no qual a existência de uma comunidade quilombola se choca com os anseios do capital imobiliário), se deu a experiência de aplicação da Lei nas escolas analisadas. Espelhando a conflitiva inserção da comunidade no município, a tônica da disciplina foi a falta de parâmetros que apontassem caminhos para o que seria trabalhado pelos professores em sala de aula - esta foi uma das maiores dificuldades mencionadas pelos professores. 


\section{REVISTA TAMOIOS}

Nossa primeira entrevista foi com o professor de História A. G., então Coordenador Municipal da disciplina. Na rede municipal de educação todas as disciplinas têm um coordenador de área que é responsável pelo acompanhamento da prática dos professores e pelo desenvolvimento de projetos com os mesmos. Na ocasião o entrevistado revelou que havia sim uma matriz curricular da disciplina Estudos Afro (ver tabelas 1 e 2) que apontava conteúdos, metodologias e procedimentos. Vejamos os pontos apresentados nesta matriz curricular.

A disciplina deveria falar da África antes dos Europeus; dos Reinos africanos; de identidade e cultura africana; tratar de história local; racismo e preconceito; falar das lutas; dos quilombos; do Movimento Negro e das políticas afirmativas, o que representaria a inserção de conteúdos e discussões até então silenciados na escola básica pelas "grades" curriculares das disciplinas convencionais.

Ao se tratar da importância da população negra na civilização egípcia berço da humanidade - buscava promover a desmistificação da África enquanto lócus da pobreza e miséria, ressaltando as cidades e a economia africana significando a revisão de conteúdos, da forma que se fala de África o que implica diretamente na construção de subjetividades, da forma que imaginamos os africanos e, conseqüentemente, os afro-descendentes.

De fato as proposições estabelecidas para a disciplina Estudos Afro nos $6^{\circ}$ e $7^{\circ}$ ano do ensino fundamental, presentes na matriz apresentada pelo entrevistado, representavam um amplo leque de temas/assuntos a serem discutidos no ensino, revendo em alguns momentos a matriz eurocentrada em que a nossa educação está calcada. 
TABELA 1 - Matriz Curricular da disciplina Estudos Afro: 6o Ano - Ensino Fundamental.

\begin{tabular}{|c|c|c|}
\hline Tema & Conteúdo & Competências e Habilidades \\
\hline Localização & $\begin{array}{l}\text { Aspectos geográficos } \\
\text { do continente africano }\end{array}$ & Identificar e localizar o continente africano \\
\hline Geografia da África & Limites geográficos & Oceanos, desertos, florestas \\
\hline $\begin{array}{l}\text { África antes da } \\
\text { chegada dos europeus }\end{array}$ & $\begin{array}{l}\text { Aspectos políticos, } \\
\text { econômicos e culturais } \\
\text { dos principais reinos } \\
\text { africanos }\end{array}$ & $\begin{array}{l}\text { Compreender os diversos reinos africanos } \\
\text { no contexto social, político e cultural }\end{array}$ \\
\hline O Egito Antigo & $\begin{array}{l}\text { Egito: a fantástica } \\
\text { civilização negra }\end{array}$ & $\begin{array}{llll}\text { Compreender o } & \text { Egito } & \text { como } & \text { parte } \\
\text { integrante da África }\end{array}$ \\
\hline A escravidão na África & $\begin{array}{l}\mathrm{O} \text { conflito entre tribos } \mathrm{e} \\
\text { reinos }\end{array}$ & $\begin{array}{l}\text { Entender os motivos da escravidão de } \\
\text { africanos no continente }\end{array}$ \\
\hline $\begin{array}{l}\text { Expansão ultramarina, } \\
\text { os portugueses e a } \\
\text { África }\end{array}$ & $\begin{array}{l}\text { A formação das } \\
\text { colônias portuguesas }\end{array}$ & $\begin{array}{l}\text { Encontro de culturas, hoje são países que } \\
\text { falam a língua portuguesa. Identificá-los no } \\
\text { mapa }\end{array}$ \\
\hline $\begin{array}{l}\text { Os africanos no Brasil } \\
\text { colônia }\end{array}$ & $\begin{array}{l}\text { Os fatores que } \\
\text { desencadearam a } \\
\text { escravidão de africanos } \\
\text { no Brasil. A história de } \\
\text { Zumbi dos Palmares }\end{array}$ & $\begin{array}{l}\text { Compreender a formação do povo } \\
\text { brasileiro }\end{array}$ \\
\hline $\begin{array}{l}\text { Influências da cultura } \\
\text { africana }\end{array}$ & $\begin{array}{l}\text { Influencia na musica, } \\
\text { dança, culinária e } \\
\text { religião }\end{array}$ & $\begin{array}{l}\text { Reconhecimento e valorização da cultura } \\
\text { africana }\end{array}$ \\
\hline A África atual & $\begin{array}{l}\text { A África urbana, a África } \\
\text { que luta pela } \\
\text { democracia }\end{array}$ & $\begin{array}{l}\text { Desmistificar a África como lugar de } \\
\text { pobreza e miséria }\end{array}$ \\
\hline $\begin{array}{l}\text { Referências africanas } \\
\text { na Região dos Lagos; } \\
\text { o africano na cidade } \\
\text { de Búzios }\end{array}$ & $\begin{array}{l}\text { História local com } \\
\text { ênfase na história e } \\
\text { cultura negra }\end{array}$ & Identidade Regional \\
\hline $\begin{array}{l}\text { Racismo/Pré- } \\
\text { conceito/Discriminação }\end{array}$ & $\begin{array}{l}\text { Abordar temas como } \\
\text { diversidades, } \\
\text { miscigenação, exclusão } \\
\text { social }\end{array}$ & $\begin{array}{l}\text { Entender } 0 \text { Brasil como um país } \\
\text { multirracial }\end{array}$ \\
\hline
\end{tabular}


TABELA 2 - Matriz Curricular da disciplina Estudos Afro: 7ํano - Ensino Fundamental

\begin{tabular}{|c|c|c|}
\hline Tema & Conteúdo & Competência e Habilidade \\
\hline $\begin{array}{l}\text { O tráfico negreiro e suas } \\
\text { peculiaridades }\end{array}$ & $\begin{array}{l}\text { As guerras tribais na África. A } \\
\text { captura dos seus habitantes. } \\
\text { A viagem e a negociação do } \\
\text { negro como mercadoria }\end{array}$ & $\begin{array}{l}\text { Analisar os conflitos tribais e } \\
\text { a necessidade de mão-de- } \\
\text { obra escrava na América }\end{array}$ \\
\hline A resistência dos negros & $\begin{array}{l}\text { As péssimas condições de } \\
\text { vida dos escravos. As fugas e } \\
\text { a formação dos quilombos }\end{array}$ & $\begin{array}{l}\text { Desmistificar a passividade } \\
\text { dos escravos. O conflito de } \\
\text { classes }\end{array}$ \\
\hline $\begin{array}{l}\text { A escravidão e o Império do } \\
\text { Brasil }\end{array}$ & $\begin{array}{l}\text { A sociedade escravista no } \\
\text { séc. XIX; as leis que } \\
\text { antecederam à abolição; o } \\
\text { processo abolicionista }\end{array}$ & $\begin{array}{l}\text { Compreender o processo de } \\
\text { transição econômica para o } \\
\text { capitalismo no Brasil }\end{array}$ \\
\hline Identidade cultural & $\begin{array}{l}\text { As influencias africanas na } \\
\text { nossa cultura; as novas } \\
\text { culturas no final do séc. } X X\end{array}$ & $\begin{array}{l}\text { Música, dança, culinária, } \\
\text { língua e religião }\end{array}$ \\
\hline O negro pós abolição & $\begin{array}{l}\text { A exclusão social dos negros; } \\
\text { a falta de perspectivas; a } \\
\text { abolição não rompe com a } \\
\text { ordem tradicional }\end{array}$ & $\begin{array}{l}\text { Reflexão sobre as diferenças } \\
\text { sociais no Brasil República }\end{array}$ \\
\hline A descolonização da África & $\begin{array}{l}\text { Compreensão da África após } \\
\text { a saída dos europeus }\end{array}$ & $\begin{array}{l}\text { A África de hoje: o desafio de } \\
\text { um grande continente }\end{array}$ \\
\hline $\begin{array}{l}\text { O negro e o Brasil do séc. } \\
X X I\end{array}$ & $\begin{array}{l}\text { Os Movimentos Negros; as } \\
\text { políticas afirmativas; o } \\
\text { resgate e a valorização da } \\
\text { cultura afro-descendente; os } \\
\text { afro-descendentes e a mídia }\end{array}$ & $\begin{array}{l}\text { O entendimento da legislação } \\
\text { nas questões de igualdade } \\
\text { racial; o caminho para a } \\
\text { verdadeira democracia racial }\end{array}$ \\
\hline
\end{tabular}

Pena que, como informado nas escolas, esta Matriz Curricular nunca chegou às mãos dos professores. E por esse motivo cada professor trabalhou "à sua maneira". Mesmo mediante práticas e metodologias tão variadas, pôdese realizar uma síntese do currículo praticado (conteúdos lecionados) pelos professores de Estudos Afro nas duas escolas analisadas. É importante frisar que os pontos de conteúdos colocados não vieram somente da fala dos professores, mas também da análise dos cadernos de seus alunos.

A partir da análise dos materiais percebeu-se um considerável distanciamento do currículo oficial (prescritivo) para o currículo praticado pelos 


\section{REVISTA TAMOIOS}

professores em sala de aula. Discussões importantes como a história local, o quilombo da Rasa, racismo, as políticas afirmativas e o Movimento Negro não figuraram enquanto conteúdo trabalhado em sala de aula.

No começo da disciplina foi comum a todos os professores, uma vez que têm formação em História, trabalhar eixos cronológicos e os Reinos africanos, porém isto foi feito de forma bastante tópica, mencionando uma ou outra característica, descrevendo um ou outro aspecto, não sendo claro nestes momentos a instauração de um debate mais aprofundado. As poucas vezes que uma relação mais complexa era mencionada eram nos momentos em que apareciam os contatos com a população branca, europeus e árabes os quais eram tidos como os que traziam técnicas de cultivo e comercialização mais aprimoradas.

Somente em dois momentos há referência a uma sociedade africana como possuindo uma organização social e econômica, quando se fala dos Reinos de Gana e Mali. Em grande parte a abordagem é feita sobre o estabelecimento de uma contribuição dos povos africanos de forma "folclorizada", como a dança, a culinária, a música e a religião.

Em outros momentos há uma valorização dos aspectos naturais da África (o que o coordenador municipal da disciplina chamou de "geografia da África"), sobretudo retratando a "África selvagem", a qual figura no imaginário mundial como lugar exótico, dos animais selvagens, da savana, dos desertos que seriam os responsáveis pela dificuldade de outros povos adentrarem 0 continente. Em nenhum momento é mencionado que o europeu encontrou resistência dos povos africanos.

E por fim, os quilombos são retratados de maneira simplória como lugar isolado onde os negros se refugiavam da escravidão, não sendo mencionada a história local do quilombo da Rasa.

\section{A experiência de aplicação da Lei nas perspectivas dos professores de Geografia e dos alunos}

E os professores de Geografia como se colocaram neste processo? É importante ressaltar que os professores de Geografia que responderam os 


\section{REVISTA TAMOIOS}

questionários e que foram entrevistados são os que lecionam para as mesmas turmas que têm aula de Estudos Afro.

Dos professores entrevistados somente um era concursado e nenhum alegou conhecer a Lei 10.639 e, portanto, não realizam nenhum trabalho para atender às suas demandas.

Do total de oito professores de Geografia, seis concordam com o fato de somente professores de história lecionarem a disciplina Estudos Afro, pois eles são "mais aptos" para tratar a questão. Somente dois acham que a Geografia tem algo a contribuir. Para cinco dos professores o livro didático é o principal material de organização do que vai ser trabalhado nas aulas de Geografia. Sinteticamente, os professores colocaram como pontos comuns entre os conteúdos de Geografia e Estudos Afro: o tráfico negreiro, aspectos sociais, formação do território brasileiro, África, questões demográficas e sociais, globalização e economia".

No que se refere à proximidade do conteúdo trabalhado em Geografia com a história local, quatro dos oito professores sabem o que é quilombo, referindo-se a este como "refúgio de escravos fugidos em lugar de difícil acesso", retratando superficialmente o que foram os quilombos, os quais eram muito complexos no que se refere a sua composição social, sua localização e suas relações comerciais. Além disso, seis dos professores não trabalham nem quilombos nem comunidades remanescentes de quilombos em nenhum momento de suas aulas.

De forma geral, os professores trabalham África segundo os determinados temas: Formação Geológica e relevo; Hidrografia, clima e vegetação; Disponibilidade de água; A colonização; A descolonização; O subdesenvolvimento; Estrutura da população; A urbanização e as cidades; A África Subsaariana e a África Branca. Como era de se esperar, após trabalharem os aspectos físico-naturais como parte introdutória ao conteúdo de África, o Continente exótico e exuberante, esta passa a ser vista a partir da sua relação com a Europa, sendo retratada posteriormente com o fim do julgo imperialista. E aí começa a aparecer a África do subdesenvolvimento, da miséria, da fome, das doenças e das guerras; para então mostrar um outro 


\section{REVISTA TAMOIOS}

lado, a "África branca", onde se tem os pequenos surtos de desenvolvimento, onde aparecem cidades, prédios, indústrias, etc.

Portanto, os professores de Geografia acabaram por não realizar nenhum trabalho que aponte para os conteúdos colocados pela Lei 10.639, praticando ainda uma Geografia que contribui para a construção de estereótipos pejorativos em relação ao povo negro e seus espaços.

E como foi o reflexo nos alunos - do $6^{\circ}$ e $7^{\circ}$ ano do segundo segmento do ensino fundamental das duas escolas analisadas - dessa experiência de aplicação da Lei 10.639? Primeiramente foi solicitado que os alunos se identificassem étnico-racialmente segundo a classificação do IBGE. O intuito era verificar se numa turma onde, para os padrões de relações raciais brasileiros, a composição majoritária era de crianças negras, se eles se identificavam como tal. O resultado foi o seguinte: $29 \%$ branco, $17 \%$ preto, $54 \%$ pardo, $0 \%$ amarelo, $0 \%$ indígena. Depois foi perguntado se os alunos tinham algum parente que eles classificariam como "preto" e $79 \%$ responderam que sim. Grande parte dos alunos tinham pai e/ou mãe pretos e, em alguns casos, usaram termos como "minha mãe é meio escurinha" ou "meu irmão é preto, mas nem tanto". O que se percebeu é que os alunos viam vários de seus parentes como pretos, mas não se identificavam como tal, tendendo mais a classificarem-se enquanto pardos, muito embora o percentual de pretos tenha sido maior que o nacional que é de $6,9 \%$, segundo dados do IBGE.

Foi perguntado sobre o que eles aprenderam na disciplina estudos Afro. A maioria foram respostas evasivas, iniciando-se com a expressão "sobre os negros", sempre mencionando negro na $3^{\text {a }}$ pessoa, como se fossem "os outros". As outras respostas que mais apareceram foram "sobre o preconceito" e "sobre a escravidão". Nenhum aluno verificou similaridade dos conteúdos de Geografia com os aprendidos na disciplina Estudos Afro.

Quando perguntado sobre os que eles entendiam sobre África, perdura a visão pejorativa, reducionista, preconceituosa e homogênea. As respostas mais comuns atrelavam a África como o lócus da pobreza, da fome, da miséria, das doenças, da escravidão.

Quando perguntado sobre a religião dos alunos, $67 \%$ é evangélica, $5 \%$ católica, 23\% respondeu que não tem religião e 5\% respondeu cristã. Quando 


\section{REVISTA TAMOIOS}

perguntado sobre o que eles achavam da música e da religião africana, muitos responderam não gostar e "parece macumba" ou então deram novamente respostas pontuais como "bom" e "legal", como se não quisessem realmente expressar a sua opinião.

No que se refere à realidade do bairro em que moram, $58 \%$ dos alunos não sabem o que é quilombo. O mesmo percentual não sabe o que é Comunidade Remanescente de Quilombo. Os 42\% que responderam saber o que é quilombo, o definiram da mesma forma que os professores, como lócus de negros fugidos em locais inóspitos.

Como constatado os alunos não assumem o compartilhamento de uma identidade negro-afrodesdendente-quilombola, mesmos os alunos cujos pais e avós integram a Comunidade Remanescente do Quilombo da Rasa, como no caso do neto da Dona Uya - presidente da comunidade quilombola - que foi um dos que responderam o questionário. Além disso, os alunos dizem não gostar do tema e muitos até mesmo desconhecem a existência de uma comunidade quilombola no bairro em que vivem. A maioria sabe que existe, mas não sabe o que é.

\section{Considerações Finais}

Através desta pesquisa foi possível verificar quão complexa é a questão da aplicação da Lei 10.639 nas escolas brasileiras. Mesmo em lugares em que ela é de alguma forma trabalhada há uma coalizão de forças e fatores que faz com que esta Lei não tenha de fato "pegado". E os motivos são variados: falta de comprometimento de alguns professores; a própria forma como o trabalho docente é organizado, onde o professor necessita trabalhar em escolas diferentes para manter um padrão de vida; a relação de trabalho, onde todos os professores de Estudos Afro são contratados; o fato de não ter uma reunião prévia entre Secretaria de Educação, a equipe pedagógica das escolas e os professores da disciplina, estabelecendo metas, o que seria trabalhado e as formas de avaliação; a não existência de um acompanhamento pedagógico nas escolas, a não disponibilidade de materiais e, principalmente, a resistência da comunidade escolar ao tema por conta de suas convicções religiosas. 
Essas implicações fazem com temas e conteúdos referentes à questão racial não sejam trabalhados e debatidos com os alunos; fazem com que haja um pacto nas escolas que se configura enquanto resistência a aplicação da Lei 10.639, mesmo após oito anos de sua aprovação.

O caso analisado por esta pesquisa contraria, de certa forma, a postura hegemônica nas escolas. Em Armação dos Búzios houve uma tentativa oficial de aplicação da Lei, que, no entanto, foi mal sucedida de acordo com os próprios professores e membros da Secretaria de Educação, sendo então a disciplina extinta no ano de 2009.

Percebe-se que ainda há muito por fazer, seja nas prescrições, seja na prática cotidiana dos professores. Embora a Lei tenha sido aprovada para a escola básica, é marcante a ausência dessas discussões na academia, sobretudo nos cursos de Licenciatura, os quais formam os aplicadores da Lei na escola básica. Além disso, não há nenhum mecanismo de avaliação e de acompanhamento da aplicação da Lei nas escolas. Portanto há uma situação de completa "frouxidão", onde maioria não trabalha a Lei e outros fazem de forma equivocada, descompromissada e não sistemática.

Diante desta realidade de total acomodação, se faz cada vez mais necessário encontrar saídas, formular propostas para que a Lei seja aplicada nas diferentes disciplinas. Como sugestão propomos a discussão realizada neste trabalho, de ver o currículo como fronteira espaço-temporal onde saberes globais e locais negociam a sua existência. Trabalhar a história local pode ser uma boa linha de crítica ao eurocentrismo e à constituição de visões mais plurais.

\section{Notas}

I - Entendemos aqui a palavra currículo como uma denotação do conteúdo de uma área de estudos particular ou referente ao programa total de uma instituição de ensino, embora uma análise mais complexa do currículo vá além da simples disposição de conteúdos.

II - Currículo prescritivo, segundo Goodson (2007), é aquele visto enquanto mecanismo de reprodução das relações de poder para a manutenção do Status Quo e instrumento de direção e controle da prática docente, onde "a especialização e o controle são inerentes ao governo central, às burocracias 


\section{REVISTA TAMOIOS}

educacionais e à comunidade universitária. Desde que ninguém desvele essa mística, os mundos da 'prescrição retórica' e da 'escolarização como prática' podem coexistir (...) as escolas são vistas como 'distribuidoras"' (GOODSON, 2007: 242)

III - A Lei Federal 10.639, aprovada em 09 de janeiro de 2003, tornou obrigatório em todo o currículo escolar, o ensino da História da África e dos Africanos e da História da Cultura Afro-Brasileira nas instituições públicas e privadas no nível básico de ensino

IV - Tal metodologia foi pensada segundo as colocações de André (1995) sobre a complexidade do cotidiano da escola.

V - Sobre as estratégias de branqueamento, Santos (2009) aponta o seguinte: "A política de branqueamento da população, guarda profundas controvérsias. Primeiramente, há controvérsias acerca das estratégias: grande parte das narrativas concentram-se na política de imigração, não contemplando as violências físicas (extermínio e subjugação de seres humanos através de confrontos armados), políticas (eliminação da representatividade e do poder dos grupos não brancos), psicológicas (inculcação de sentimentos de superioridade e inferioridade com base em pertencimento racial) e culturais (eliminação e inferiorização de práticas manifestações, comportamentos, etc.)." (SANTOS, 2009: 58)

\section{Referência Bibliográficas}

- ANDRÉ, Marli Eliza D. A. de. Etnografia da prática escolar - Campinas, SP: Papirus, 1995.

- GROSFOGUEL, Ramón. Descolonizando los paradigmas de la economíapolítica: transmodernidad, pensamiento fronterizo y colonialidad global. 2005, Disponível em: http://www.grupalfa.com.br/arquivos/Congresso trabalhosll/ palestras/Ramon.pdf

- IVOR, Goodson. Currículo, narrativa e o futuro social. Revista Brasileira de Educação v. 12 n. 35 maio/ago. 2007

- LOPES, Alice Casimiro. Discursos nas políticas de currículo. Currículo sem Fronteiras, v.6, n.2, pp.33-52, Jul/Dez 2006

- MACEDO, Elizabeth. Currículo: Política, Cultura e Poder - Currículo sem Fronteiras, v.6, n.2, pp.98-113, Jul/Dez 2006 
- MIGNOLO, Walter. Os esplendores e as misérias da "ciência": colonialidade, geopolítica do conhecimento e pluri-versalidade epistêmica In SANTOS, Boaventura de Sousa (org.). Conhecimento prudente para uma vida decente: um discurso sobre as ciências revisitado. 2 ed. - São Paulo: Cortez, 2006.

- NORBERTO, Joaquim. Memória histórica e documentada das aldeias de índios do Rio de Janeiro - Revista do IHGB, n. 14, 3ª série.

- OSLENDER, Ulrich. Espacio, lugar y movimientos sociales: hacia uma "espacialidad de resistencia". Revista Electrónica de Geografía y Ciencias Sociales, Universidade de Barcelona - Vol. VI, num. 115, 1 de junio de 2002.

- Pereira, Amauri. Quem não pode atalhar, arrodeia!: reflexões sobre o desafio da práxis dos educadores agentes da Lei 10.639/03. Trabalho apresentado no 30ํ Encontro Anual da ANPUR. Caxambu, 2007.

- PORTO-GONÇALVES, C. W. A geograficidade do social: uma contribuição para o debate metodológico sobre estudos de conflito e movimentos sociais na América Latina. In: SEOANE, J. Movimientos Sociales y Conflicto en América Latina. Buenos Aires: CLACSO, 2004. p. 261-277.

- SANTOS, Boa Ventura S. Pela mão de Alice. São Paulo: Cortez, 2000.

- SANTOS, Renato Emerson N. dos. Rediscutindo o Ensino de Geografia:

Temas da Lei 10.639. 2009 (Mimeo) 